\title{
Exploring Cultural Competence from a Sociological Point of View
}

\author{
Prof. Connie Moloi \\ Vaal University of Technology, Faculty of Human Sciences \\ Vanderbijlpark, 1900 South Africa \\ Email: conniem@vut.ac.za
}

Mrs. Mariette Bam

Vaal University of Technology, Faculty of Human Sciences

Vanderbijlpark, 1900 South Africa

Email:kierrie@gmail.com

Doi:10.5901/mjss.2014.v5n3p332

\begin{abstract}
This article describes cultural competence from a sociological perspective. Given the diversity in all aspects of life in South Africa the researchers argue that mastering cultural competence could address many of the misunderstandings that normally occur among people of different cultures. A review of the literature shows that cultural competence is about the ability to work effectively across cultures; it is an approach that enables one to learn to communicate and work respectfully with people whose cultures differ from one's own. Furthermore, cultural competence is about people's own feelings of competence which are based on positive attitudes and self-confidence. The authors argue that the development of cultural competency is a long journey that requires insight, emotional maturity, caring and a way of being. Within organisations cultural competence is the ability to create practice and policies that are more accessible to different populations for appropriate and effective crosscultural situations.
\end{abstract}

Keywords: Cultural competence, multi-culturalism, cultural differences, communication competence, maturity

\section{Introduction}

This paper explores the subject of cultural competence from a sociological point of view. Lustig \& Koester (2006:24-25) see culture as a learned set of shared interpretations about beliefs, values, norms and social practices, which affects the behaviour of a relatively large group of people. Olsen, Bhattacharya \& Scharf (2006:3) add that culture can refer to an individual's race, class, gender, sexual orientation, religion, age, and so forth. According to Samovar \& Porter (1988:19), culture manifests itself in patterns of language and in forms of activity and behaviour that act as models of common adaptive acts and the styles of communication that enable people to live in a society within a geographical area at a given state of technical development, in a certain moment of time. Samovar \& Porter (1988:19) point out, moreover, that culture is persistent, enduring and omnipresent as it includes all of the behavioural reinforcements received during the course of a lifetime. Culture is also used in conjunction with specific places and categories of people, although the word can be used to emphasise differences as well (Ferrante, 2003:69). The development of cultural competency may be best thought of, not as arriving at a set of skills and knowledge, but rather as a journey and a way of being (Olsen, Bhattacharya \& Scharf, 2006).

Ferrante (2003:69) observes that the use of the word indicates that we think of culture as having clear boundaries, that it explains certain behaviour and provides a blueprint for living that people follow, but that interaction between people of different cultures can be problematic. Lustig \& Koester (2006:25) suggest that humans are not born with the genetic imprint of a particular culture but that it is learned. The definition that Olsen, Bhattacharya \& Scharf (2006:4) give of culture is that it is all the learned beliefs, traditions, language, values, customs, rituals, manners of interacting, forms of communication, expectations of behaviours, roles and relationships commonly shared among members of a particular group, and often passed on from generation to generation. This includes ways parents discipline their children, the structure of family relationships, expectations of what it means to be a boy or a girl, values about health and approaches to healing, body language, what types of things get said and what types go unspoken. Olsen et al. (2006:5) list five important things that should be understood about culture: (i) everyone has a culture; (ii) There is diversity within culture; 
(iii) cultures are not static; (iv) cultural differences are complicated by differences in status and power; and (v) cultures are not determinative.

Olsen et al. (2006) conclude that the behaviour of the group becomes the norm and often becomes unconscious and invisible to the people within that culture. Samovar \& Porter (1994:12) maintain that there are six characteristics of culture: culture is learned, transmissible, dynamic, selective, interrelated and ethnocentric. Ferrante (2003:69) explains a culture gap as the difference in behaving and thinking within a culture group in different times. An example is seen in the dress code of South African universities. In the seventies dress codes were very formal: women were allowed to wear pants only as part of a tailored suit with a jacket and no jeans were allowed, even for men. Nowadays, students even wear slippers to classes. Lustig \& Koester (2006:162) describe culture shock as sustained intercultural contact that requires a total immersion in another culture, resulting in the loss of familiar signs and symbols of social intercourse. Ferrante (2003:69) believes that culture shock occurs when a person is confused by the different way of life of another group. Furnham \& Bochner (1983:162) explain that the term refers to the idea that entering into a new culture is a potentially confusing and disorientating experience.

Olsen et al. (2006:3) define cultural competence as the ability to work effectively across cultures and as an approach to learning, communicating and working respectfully with people from cultures different from one's own. They further suggest that cultural competence in organisations means to create practices and policies that are more accessible to different populations for appropriate and effective communication in cross-cultural situations. Furthermore, an individual can feel culturally competent as a result of learning the customs and traditions of different cultures and to communicate more respectfully and appropriately with members of different cultures. Because of continued change, the work of bridging cultures can never be done in the sense that there is nothing more to learn about a culture; there is also always something new to learn about one's own culture. The development of cultural competency may be best thought of as a journey into the discovery of a way of being.

According to Brislin (1987:284), cultural competence is about people's own feelings of competence, which are based on positive attitudes and self-confidence. Brislin (1987:285) proposes a general definition of cultural competence: it is a dynamic process that draws on the individual's cognitive, linguistic and social capabilities and. the translation of these capabilities into functionally appropriate interpersonal strategies for use in particular situations or socio-cultural contexts. Thus it is the ability to draw on one's capabilities and social knowledge and to combine them for strategies in individual processes, flexibility and development.

\section{Why do Cultures Differ?}

Lustig \& Koester (2006:33) answer this question by observing that cultures look, think and communicate differently because they have the need to accommodate and adapt to the pressures and forces that influence them as a whole. Lustig \& Koester (2006:34-44) name the forces that influence cultures in this way. History is made up of the unique experiences that become part of a culture's collective wisdom. These are things such as wars, inheritance rules, religious practices, economic consequences, prior events, legislative acts and the allocation of power. Ecology is the external environment in which a culture lives. It includes overall climate, changing weather patterns, prevailing land and water formations and the availability/unavailability of certain foods and raw materials. Technology is made up of inventions created or borrowed from other cultures and includes tools, weapons, hydraulic techniques, navigational aids, paper clips, barbed wire, stirrups and microchips. Biology is the inherited characteristics that cultural members share; people with a common ancestry have similar genetic compositions. These often arise as an adaptation to environmental forces and are evident in biological attributes often called race. Institutional networks are the formal organisations in society that structure activities for a large number of people. These are government, education, religion, work, professional associations and social organisations. Interpersonal communication includes patterns such as face-to-face verbal and nonverbal coding systems that are developed to convey meanings and intentions. These patterns include links among parents, siblings, peers, teachers, relatives, neighbours, employers, authority figures and other social contacts.

\section{Development of Cultural Competence}

Cultural competence development studies were conducted by the Nurses' Association of Ontario (2007:17) to improve health care in Canada because of future predictions of population growth that will be the consequence of immigration from countries where most citizens are not white and speak neither English nor French as their first language. According to the research there are five very important aspects in the development of cultural competence within Canada: 
inclusivity, respect, equity, valuing differences, and commitment. It was concluded that embracing cultural diversity and developing cultural competence are key components for healthy work environments because they influence leadership, teamwork and professional practices. (Nurses' Association of Ontario, 2007:17-56)

Development in cultural competence became an important study in health care because of patient dissatisfaction, poor comprehension and adherence and lower-quality care. There was a clear link drawn between cultural competence, quality improvement and the goal of eliminating racial and ethnical disparities. It was found that an understanding of communities being served and of the socio-cultural influences on individual patients' health beliefs and behaviours is required to understand cultural competence in health care (Betancourt, 2002:5-14). According to Samovar \& Porter (1994:43), communication competence requires motivation and knowledge, as well as the skill to demonstrate what behaviour is appropriate and effective. Olsen et al. (2006:4) noted that there is more work to be done to become more culturally responsive and respectful in order to offer accessible and appropriate services for diverse clients (patients) and it begins with the recognition that the goal is healthy outcomes for children and families.

\section{Competencies in Health Care}

The study by the Nurses' Association of Ontario (2007) listed tools which, in their opinion, are needed to assist in developing skills to understand diversity. By developing the following competencies and behaviours one will be able to appreciate other cultures and handle situations in a more appropriate manner. First, starting with the individual, there must be self-awareness and one should perform self-reflection on one's own beliefs and values and incorporate feedback from peers. Expressing an awareness of one's own views and continually exploring, through reflection and feedback, how one's own views affect others can improve the ability to help others. Furthermore, there should be culture awareness and this can be done by identifying cultural differences among clients and colleagues as well as by exploring strategies to resolve conflicts that arise between people of different cultural groups. Identification and guidance must be sought in the support, knowledge and skills of role models who demonstrate cultural proficiency. The recognition and addressing of discrimination, racist behaviours and institutional practices in an appropriate manner is a very important skill to acquire. The development of communication skills is of utmost importance, together with respect for each culture. Respecting a culture and cultural differences makes it easy for both parties to accept each another and reduces misunderstandings. Wallace ( $n . d: 2)$ notes that being competent includes using appropriate and effective behaviour in a specific context, and having appropriate knowledge, feelings and intentions and good performance. In order to acquire the skill of being culturally competent, a person should be aware of others, mature enough to understand them and able to communicate effectively.

\section{Cultural Awareness}

Quappe \& Cantatore (2005:1), in their discussion on cultural awareness, argue that it is the foundation of communication and that it involves the ability to stand back from oneself and to become aware of cultural values, beliefs and perceptions. Cultural awareness is said to become central when there is interaction between people of different cultures and when they observe the way they experience things that they do in different ways. Misunderstandings arise when people behave in ways that are acceptable to them but inappropriate to others, or when one uses one's own meanings to make sense of another's reality; being aware of these behaviours reduces misunderstandings. A lack of such awareness can cause multiple problems; for instance, in the white South African culture, slaughtering animals for any purpose other than food is considered evil and an abominable act. Some black South Africans, on the other hand, slaughter animals because they believe certain parts of the animal can enhance their masculinity or improve their love life and it is also regarded as an offering to please their ancestors. Lustig \& Koester (2006:27) explain that such beliefs refer to how a group understands what is true and false in its world.

\section{Gay Awareness}

Majors (1994:165-169) investigates another form of cultural awareness: awareness of the gay community or gay culture. Majors (1994:165) says the reference is made because, when gays are spoken about, they are referred to as part of a gay culture/community, and explains that growing up gay in some countries is like growing up in a different culture. According to Majors (1994:166), there has been enormous pressure from heterosexual cultures to conform to a "normal" sexuality and many gays had to hide who they are because of the hostility towards them. Majors (1994:167) argues that 
although times have changed in South Africa, it is still typically a great struggle for most gays to be accepted. Some people still find it difficult to understand gay people and are not willing to respect their differences. This is an important issue to be addressed in cultural competence. Being respectful of different lifestyles does not imply agreement with them, but cultural competence starts with accepting differences. The best way to become aware is to assume differences until similarities are proven. People who become culturally aware realise that people are not all the same. Similarities and differences are both important and there are multiple ways to reach the same goals in life. (Quappe \& Cantatore 2005:1).

\section{Cultural Communication}

Wallace (n.d.) defines cultural communication as "a symbolic process in which the degree of difference between people is large and important enough to create dissimilar interpretations and expectations about what are regarded as competent behaviours that should be used to create shared meanings." Barnlund (1988:7) explains that every culture will communicate to express the purpose and conduct of its affairs and cultures exists primarily to create and preserve common systems of symbols by which their members can assign and exchange meanings. Lustig \& Koester (2006:227) observe that there are vast cultural differences in vocalic behaviour and that some languages are very tonal, meaning that the same word can have different meanings when it is spoken in a different tone; they add that there is also a culture difference in the loudness and frequency of speaking. For instance, in white South African cultures it is considered rude to talk or shout very loudly whereas in black South African cultures talking loudly is encouraged because talking softly means that one is gossiping. Lustig (1988:60) points out that when two people are from different cultures, their value differences may prevent the achievement of rational agreement on important issues.

On the subject of communication, Brislin (1987:284) argues that attitudes and learning a new language are strongly related because people with favourable attitudes towards a certain culture will learn the language faster than those with unfavourable attitudes. A guidebook for providers of services to older Americans (2001:23-24) points out ways to be effective when communicating with different cultures, the most important of which is the willingness to listen and learn. Other points are to be open, honest, respectful, nonjudgmental and observant. Letting other people know that one is interested in what is said helps to build trust. When communicating with other cultures, to avoid discrimination one should be careful not to make assumptions, as illustrated below:

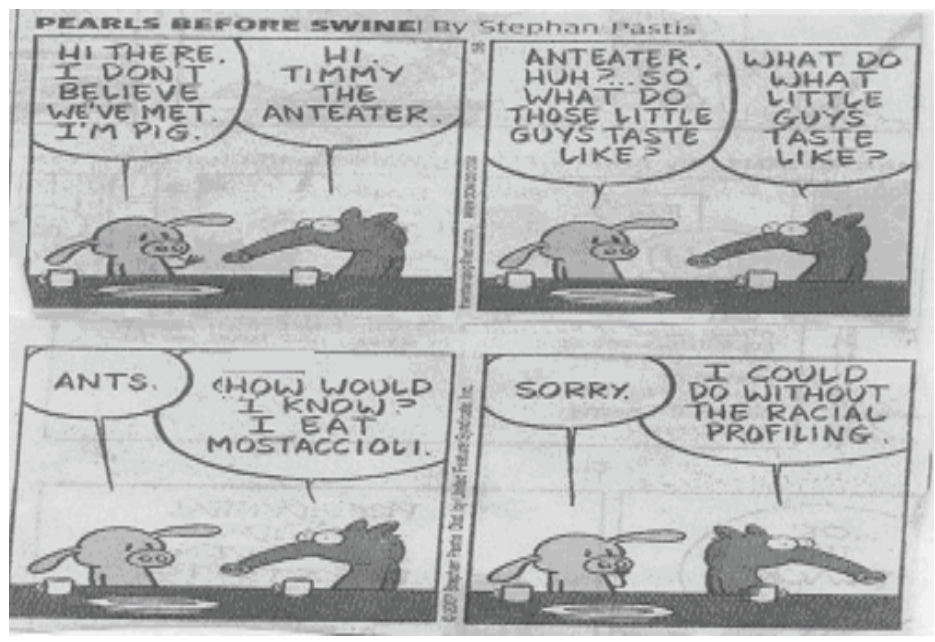

\section{Cultural Maturity}

An anonymous contributor to Wikipedia (2008) describes maturity as a term used in psychology to indicate that a person responds to the circumstances or environment in an appropriate manner. Morler (2002:1-2) states that emotional maturity is a conscious choice one has to make. Jayaram (2008) maintains that immaturity is sometimes part of groups and nations and results in misery and bloodshed. Jayaram (2008) defines maturity as awareness and understanding, listing 
the following as characteristics of maturity:

1. Being realistic and in touch with reality as well as being guided by facts;

2. Being responsible for oneself and others;

3. Willingness to examine others' beliefs, fallacies, prejudices and assumptive behaviour in an objective way;

4. Being assertive without being aggressive and being open-minded and flexible towards others.

As people are part of a society made up of various cultures, it is important to make the conscious choice of being mature and behaving appropriately towards others to avoid conflict. Maturity is realising that everyone deserves a place in the sun.

\section{Managing Diverse Diversity as a Core of Leadership}

The workplace is the place where most people interact with different cultures and where cultures conflict; the difference in cultures has one of the strongest impacts on how successful a business is. Cox (1994:11) says that managing diversity is a high-priority issue for organisations and that by managing diversity one can maximise the ability of employees. Cox (1994:12) adds that the many goals of an organisation should include the objectives of promoting fairness and improving economic opportunities for underachieving members. Cox (1994:25) explains that this is of importance because the attitudes of the workers improve, as well as commitment and job satisfaction.

One of the examples of a situation where leadership can be an issue in the workplace is when a white female is in charge. In recent years it has become acceptable for females to be authority figures but in some African and Asian cultures this is not acceptable and in many instances it has caused respect issues. This is even more noticeable in educational environments. In some white cultures the female is seen as the teacher and this opposes the traditional black culture where the male has the authority of the teacher. Even today, in South Africa's educational institutions, it is a challenge to be a female teacher within a black male-dominated society.

\section{Why Cultural Knowledge is Important?}

Brislin (1987:284) maintains that favourable attitudes regarding language and an increasing knowledge base are critical and that many adjustment problems stem from ignorance of basic facts which can easily be learned by people willing to make an effort. Brislin (1987:285) believes that people must be able to meet their everyday needs and to achieve their goals if they want it to be meaningful in any social context outside of their own culture. Samovar \& Porter (1994:43) argue that cultural identity is an approach that can help us better analyse others' conduct and decide how to do what is mutually competent. According to Furnham \& Bochner (1983:166), individuals like businessmen and diplomats are highly skilled in the verbal and nonverbal facets of interaction in their own societies but find their inadequacy in a new culture very frustrating and embarrassing. Furnham \& Bochner (1983:166) explain that ordinary things can suddenly become major obstacles for such people and advise that they be given training in those skills that are lacking.

\section{Conclusion}

In order to have respect for people of different cultures it is important that a level of emotional intelligence and maturity is achieved. We argue that if people were to appreciate each other's backgrounds, there would be fewer misunderstandings and people would be able to live together in harmony. Communicating on levels that will be helpful to individuals and communities is a goal that the understanding of social competence can help achieve. Cultural competency is a process made up of various aspects that flow together. These include communication, maturity, understanding and awareness. What better way to start working on this goal than by understanding and applying cultural competence in everyday life.

\section{References}

Anon. 2008. Definition of maturity. http://en.wikipedia.org/wiki/Maturity [Online] Accessed: May 15, 2008

Anon. 2001. A guidebook for providers of services to older Americans and their families. http://www.aoa.gov/PROF/adddiv/cultural/CCguidebook.pdf [Online] Accessed: May 15, 2008

Barnlund, D.C. 1975. Communication in a global village. In Samovar, L.A. \& Porter, R.E. $5^{\text {th }}$ ed. Intercultural communication: a reader. California: Wadsworth.

BETANCOURT, J.R. 2002. Cultural competence in health care: 
emerging frameworks and practical approaches. [Online] www.commonwealthfund.org/usr_doc/betancourt_culturalcompetence 576.pdf?section=4039 Accessed: May 15, 2008

Brislin, R.W. 1987. Cross-cultural encounters. New York: Pergamon Press.

Cox, T. 1994. Cultural diversity in organizations. California: Berret-Koehler Publishers.

Ferrante, J. 2003. Sociology a global perspective. U.S.A.: Thompson/Wadsworth.

Furnham, A. \& Bochner, S. 1983.Social Difficulty in a foreign culture: an empirical analysis of culture shock. In Bochner, S. (ed.) Cultures in contact: studies in cross-cultural interaction. Oxford: Pergamon Press.

Jayaram, V. 2008. Maturity of mind and adult behaviour [Online] http://www.hinduwebsite.com/selfdevt/maturity.asp Accessed: May 21, 2008

Haglund, E. 1984. Japan: cultural considerations. In Samovar, L.A. \& Porter, R.E. $5^{\text {th }}$ ed. Intercultural communication: a reader. California: Wadsworth.

Lustig, M.W. 1988. Value differences in intercultural communication. In Samovar, L.A. \& Porter, R.E. $5^{\text {th }}$ ed. Intercultural communication: a reader. California: Wadsworth.

Lustig, M.W. 2006. Intercultural competence: interpersonal communication across cultures. $5^{\text {th }}$ ed. Boston : Pearson, Allyn \& Bacon

MAJORS, R.E. 1994. Discovering gay culture in America. In Samovar, L.A. \& Porter, R.E. $7^{\text {th }}$ ed. Intercultural communication: a reader. California: Wadsworth.

Morler, E.E. 2002. Emotional maturity is a conscious choice. [Online] www.springerlink.com/index/J5740K7387H2435P.pdf Available: May 19, 2008

Nurses' Association of Toronto. 2007. Embracing cultural diversity in health care: developing cultural competence. http://www.rnao.org/Storage/29/2336_BPG_Embracing_Cultural_Diversity.pdf

[Online] Accessed: May 15, 2008

Olsen, L., Bhattacharya, J. \& Scharf, A. 2006. Competency, what it is and why it matters. [Online] http://www.lpfch.org/informed /culturalcompetency.pdf Accessed: November 11, 2008

QUAPPE, S. \& CANTATORE, G. 2005. What is cultural awareness, anyway? How do I build it? http://www.culturosity.com/pdfs What\%20is\%20Cultural\%20Awareness.pdf

Date of access: 11 November 2008.

Samovar, L.A. \& Porter, R.E.1988. Intercultural communication: a reader. $5^{\text {th }}$ ed. California: Wadsworth.

Samovar, L.A. \& Porter, R.E.1994. Intercultural communication: a reader. $7^{\text {th }}$ ed. California: Wadsworth.

Wallace, T. (n.d.) Cultural concept. [Online] http://www4.ncsu.edu/ twallace/ANT252\%20Lesson\%20three_Culture.pdf Accessed: November 11, 2008 